\title{
Choledochoduodenostomy for the treatment of portal cavernoma biliary stenosis to avoid bloody ERCP
}

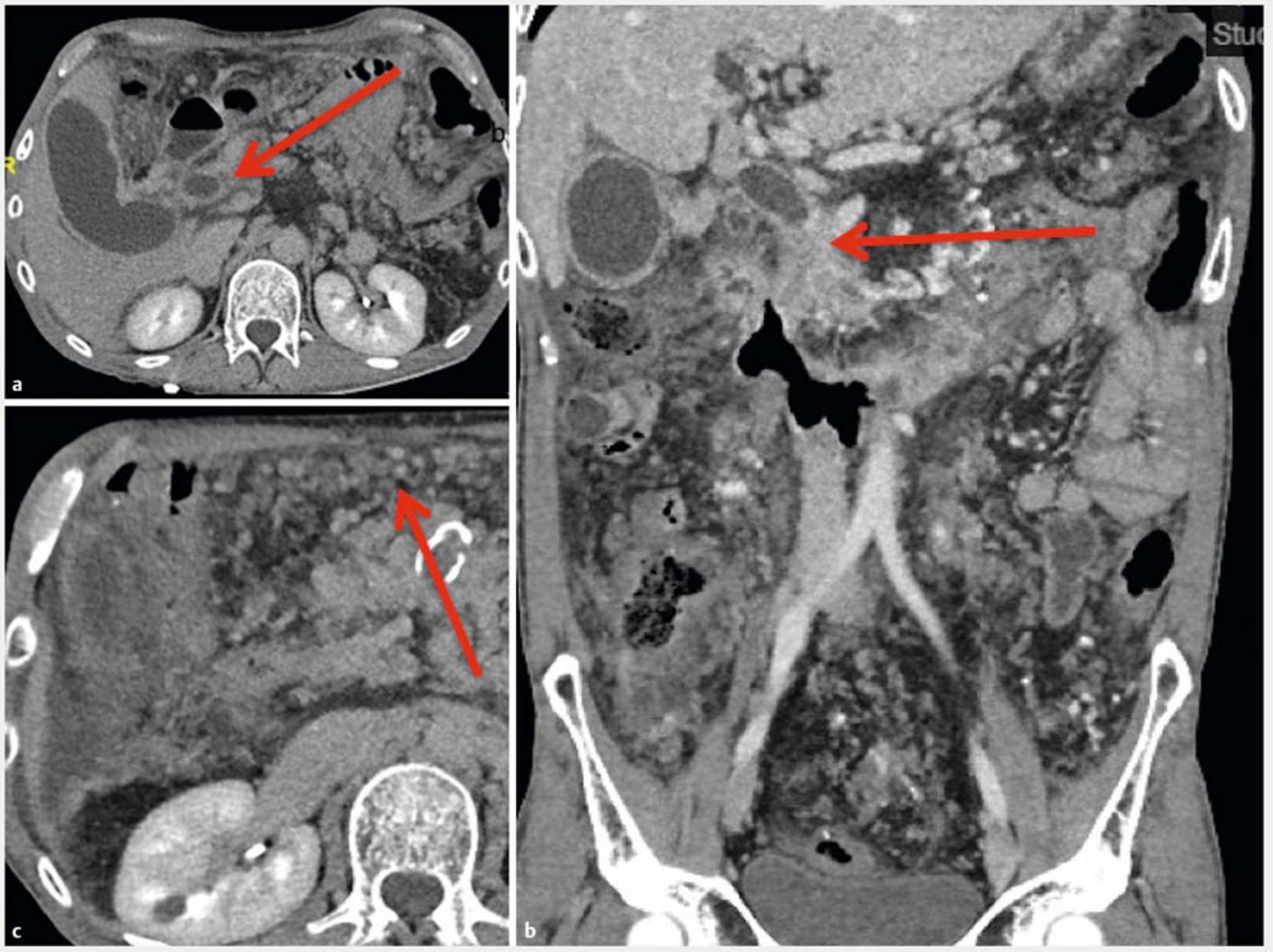

- Fig. 1 The cavernoma on computed tomography scan. a, b Bile duct dilation above the cavernoma (arrows). c Varices (arrow).

Endoscopic ultrasound-guided biliary drainage (EUS-BD) has emerged as an alternative to endoscopic retrograde cholangiopancreatography (ERCP) in cases of cannulation failures [1-3]. Two options are possible: choledochoduodenostomy or hepaticogastrostomy; however, these procedures are associated with higher morbidity, including bleeding [4] and bile leakage.

We report here the case of a 54-year-old man who presented with a portal cavernoma of unknown origin since 1987. The patient had undergone porto-cave diversion with splenectomy in 1989. Despite this treatment, he developed severe portal hypertension with several episodes of bleeding (\$ Fig. 1). In 2013, he suffered from angiocholitis related to a bile duct stenosis due to his cavernoma. Lithiasis appeared above the stenosis and required several therapeutic ERCPs with stent insertion ( $\mathbf{F i g . 2}$ ). In June 2017, during stone extraction, a severe acute bleeding with hemodynamic collapse related to pericholedochal varice rupture was treated by metallic stent compression. The stent was removed 6 months later because of occlusion. After recurrence of angiocholitis within 3 months, a multidisciplinary team decided to attempt EUS-guided drainage, considering the high risk of bleeding with ERCP ( video 1).

We first attempted hepaticogastrostomy but liver fibrosis prevented direct access to the dilated duct. Then, we converted to choledochoduodenostomy, as an area free from varices was found in the duodenal bulb. After puncture, a cystotome was used before delivering a covered metal stent. Good biliary drainage was 

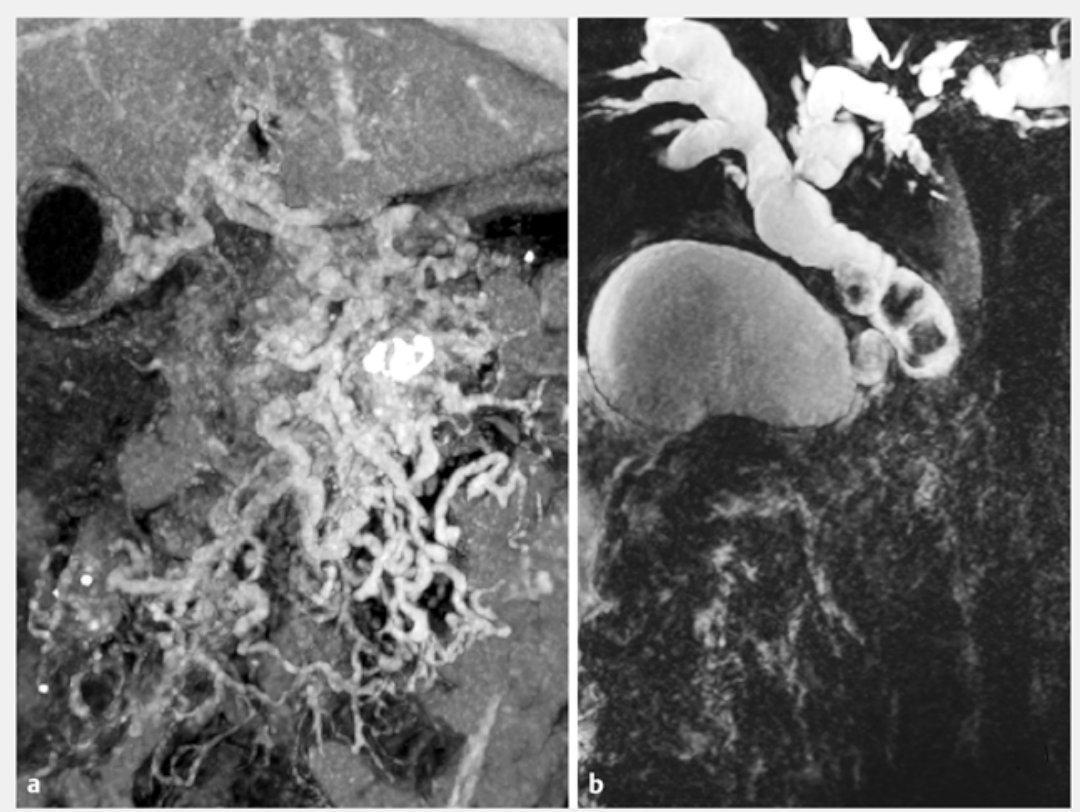

- Fig. 2 Image reconstruction. a Computed tomography reconstruction of the cavernoma. b Magnetic resonance imaging of the stenosis with stones.

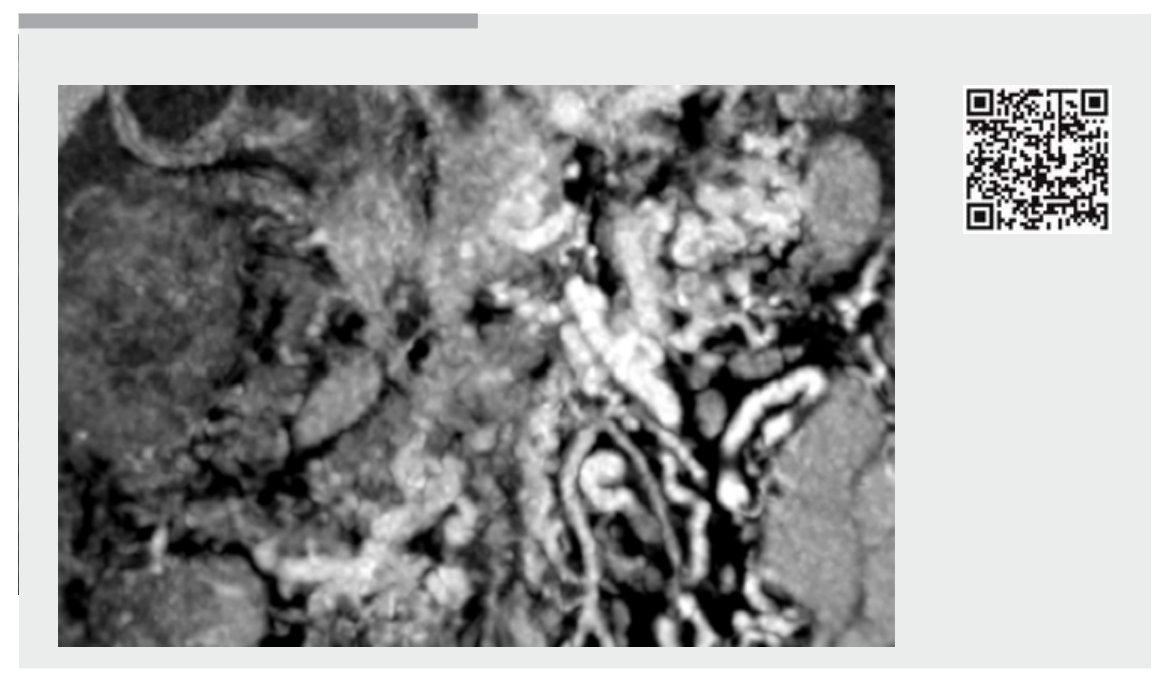

Video 1 Endoscopic ultrasound drainage of the bile duct above the cavernoma. achieved without any bleeding. Three months later, angiocholitis occurred as a result of stent occlusion by the stones that had not been extracted previously. Stent exchange resulted in clearing of stones from the bile duct and resolution of symptoms.

Portal cavernoma is a rare cause of biliary stenosis and highly challenging to treat, with frequent recurrences [5]. Proposing EUS-guided drainage to drain the bile duct above the cavernoma could be an alternative to ERCP to prevent intraductal variceal bleeding.

Endoscopy_UCTN_Code_TTT_1AR_2AK

Competing interests

\section{None}

The authors

Marie Napoléon ${ }^{1}$, Jérôme Dumortier ${ }^{2}$, Florian Rostain ${ }^{2}$, Jérôme Rivory², Thierry Ponchon ${ }^{2}$, Hélène Gimonet ${ }^{3}$, Mathieu Pioche ${ }^{2,4}$

1 Department of Digestive Physiology, Edouard Herriot Hospital, Lyon, France

2 Department of Hepatology and Gastroenterology, Edouard Herriot Hospital, Lyon, France

3 Department of Radiology, Edouard Herriot Hospital, Lyon, France

4 Inserm U1032, LabTau, Lyon, France

Corresponding author

Mathieu Pioche, MD

Endoscopy Unit - Digestive Disease Department, Pavillon L - Edouard Herriot Hospital, 69437 Lyon Cedex, France Fax: +33-4-72110147 mathieu.pioche@chu-lyon.fr 


\section{References}

[1] Poincloux L, Rouquette O, Buc E et al. Endoscopic ultrasound-guided biliary drainage after failed ERCP: cumulative experience of 101 procedures at a single center. Endoscopy 2015; 47: $794-801$

[2] Giovannini M, Dotti M, Bories E et al. Hepaticogastrostomy by echo-endoscopy as a palliative treatment in a patient with metastatic biliary obstruction. Endoscopy 2003; 35: $1076-1078$

[3] Bories E, Pesenti C, Caillol F et al. Transgastric endoscopic ultrasonography-guided biliary drainage: results of a pilot study. Endoscopy 2007; 39: 287-291

[4] Fine C, Rivory J, Forestier ] et al. Endoscopic management of gastric wall bleeding and stent blood clot occlusion after endoscopic ultrasound-guided hepaticogastrostomy. Endoscopy 2016; 48 (Suppl. 01): E351 E352

[5] Dumortier J, Vaillant E, Boillot O et al. Diagnosis and treatment of biliary obstruction caused by portal cavernoma. Endoscopy 2003; 35: 446-450

\section{Bibliography}

DOI https://doi.org/10.1055/a-0651-0284

Published online: 10.8.2018

Endoscopy 2018; 50: E289-E291

(c) Georg Thieme Verlag KG

Stuttgart · New York

ISSN 0013-726X
ENDOSCOPY E-VIDEOS

https://eref.thieme.de/e-videos

而回 Endoscopy E-Videos is a free access online section, reporting G.: on interesting cases and new techniques in gastroenterological endoscopy. All papers include a high quality video and all contributions are freely accessible online.

This section has its own submission website at

https://mc.manuscriptcentral.com/e-videos 